\title{
"Para quem vai trabalhar na feira... essa educação está boa demais": a política educacional na sustentação da divisão de classes
}

\author{
Selma Borghi Venco* \\ Reginaldo Fernando Carneiro $^{* *}$
}

\begin{abstract}
Resumo
O artigo tem como escopo debater a política educacional brasileira contextualizada em sua história recente e, focalizando, mais especificamente as formas de padronização da educação, particularmente a Base Nacional Curricular Comum (BNCC). A hipótese que orientou o estudo, de caráter documental, centra-se na perspectiva que o projeto neoliberal persegue as demandas internacionais voltadas à lógica da mensuração de resultados e padronização mundial da educação, sendo a BNCC ferramenta fulcral nessa edificação. Constata-se que nessa perspectiva o Brasil opta, seguindo sua tradição, por uma educação submissa aos países centrais e permanece se inscrevendo subalternamente na divisão internacional do trabalho.

Palavras-chave: Política educacional; Base Nacional Comum Curricular; Padronização da educação.

"For those who will work at the street market ... this education is so good": the educational policy in support of the social classes'division
\end{abstract}

\begin{abstract}
The article argues the Brazilian educational policy contextualized in its recent history and, focusing more specifically the forms of standardization of education, particularly the National Curricular Common Base. The hypothesis that guided the study, as a documental research, is that the neoliberal project pursues the international demands, intended for the logic of the measurement of results and global standardization of education, and BNCC is a pivotal tool in this construction. It is noted that in this perspective Brazil opts, according to its tradition, for a submissive education to the central countries and continues subscribing itself subalternly in the international division of labor.

Keywords: Educational policy; National Common Curricular Base; Standardization.
\end{abstract}

Manhê! Tirei um dez na prova. Me dei bem, tirei um cem e eu quero ver quem me reprova.

Decorei toda a lição.

Não errei nenhuma questão.

Não aprendi nada de bom.

Mas tirei dez, (Boa, filhão!!!).

Quase tudo que aprendi, amanhã eu já esqueci. Decorei, copiei, memorizei, mas não entendi. Estudo Errado, Gabriel, o pensador

\section{Introdução}

O propósito do presente artigo é debater a política educacional construída no decorrer da história do país que, paulatinamente, soma novos passos em direção ao atendimento de projetos de sociedade, que se encontram em disputa, aqui focalizando especificamente a nova etapa desse processo: a aprovação da Base Nacional Curricular Comum, doravante denominada BNCC.

A hipótese orientadora da análise apoia-se na estreita relação da adoção de um projeto

\footnotetext{
"Endereço Eletrônico: selma.venco@gmail.com

***Endereço Eletrônico: reginaldo_carneiro@yahoo.com.br
}

neoliberal para a educação, o qual persegue as demandas internacionais voltadas à lógica da mensuração de resultados e padronização mundial da educação, sendo a BNCC ferramenta fulcral nessa edificação.

Apoiamo-nos em Fonseca (2009) cuja reflexão sobre a perspectiva de qualidade da educação articula a política educacional e o projeto de desenvolvimento econômico nacionais. A argumentação empreendida pela autora ressalta que a educação se estrutura e se desenvolve, historicamente, em bases para o atendimento ao 
mercado de trabalho. No Estado Novo, a educação básica organizou-se em ramos profissionais assingelando os conteúdos propedêuticos, com vistas a dar sustentação ao processo de industrialização em curso.

Não obstante, às elites havia outra educação distante da formação profissionalizante e, aqui compreendida como formada para ocupar níveis elevados da pirâmide social. A mesma matriz persiste no governo Juscelino Kubitschek (19561961) destacando que a educação deveria "produzir competências técnicas para o emprego, de forma a agregar valor aos recursos humanos no mercado" (FONSECA, 2009, p. 158). O vocabulário empregado, oriundo da economia, indica a adesão à teoria do capital humano, que compreende a escola como produtora de instrução e seu respectivo valor econômico (SCHULTZ, 1973).

O formulador da teoria, Theodore Schultz (1902-1998) aponta para a relação entre os investimentos realizados em educação e saúde como fator para o crescimento econômico e aumento da produtividade individual, considerando, de um lado, o aspecto quantitativo referente ao total de anos de estudo das populações investigadas, mas desprezando as diferenciações qualitativas da oferta e, sobretudo as situações de desigualdade social.

Tal perspectiva teórica, compreende-se, é intrínseca a um dos valores que sustentam o capitalismo: o individualismo. Isso porque concebe o indivíduo como responsável pelo investimento em si mesmo.

A nítida inspiração em Adam Smith que, em 1776 (1993, p. 63), ressaltava a incumbência individual para acumular riqueza às nações:

O esforço natural de cada indivíduo no sentido de melhorar sua própria condição constitui, quando lhe é permitido exercer-se com liberdade e segurança, um princípio tão poderoso que, sozinho e sem ajuda, é não só capaz de levar a sociedade à riqueza e prosperidade, mas também de ultrapassar centenas de obstáculos inoportunos que a insensatez das leis humanas demasiadas vezes opõe à sua atividade.

Consoante a Lima (1980), a imprecisão da proposta reside no fato de considerar que cada um tenha autonomia, lato sensu, para decidir e permanecer se escolarizando o tempo que considerasse necessário: "é difícil crer que as pessoas tenham realmente esse tipo de escolha à disposição" (p. 225).

Essa será, portanto, no nosso entendimento, a teoria orientadora das políticas a partir de então, das quais passamos a destacar certos aspectos.

\section{Sincronização de movimentos: racionalidade e padronização}

A política monetária adotada no Acordo Bretton Woods (1944) estabelecia paridade do dólar ao ouro. Os excessos - de ordens diversas, mas em particular a elevada emissão de dólares -, praticados pelos Estados Unidos durante a Guerra do Vietnã levaram o conjunto de países participantes do Acordo a romper com a referida equivalência e descerraram uma crise econômica de alta amplitude nos anos 1970. Essa situação, somada às questões concernentes ao embargo do fornecimento de petróleo aos Estados Unidos e outros países centrais na economia, levou ao acúmulo de importantes déficits nas décadas seguintes.

A crise, nesse período, é estrutural. Segundo Santos (2001), nessa fase do capitalismo a respectiva sustentação do sistema se dá pelo despotismo do dinheiro e da informação, que conduzem ao pensamento único.

A globalização propalada como integradora, responsável pela transposição de barreiras e pela redução de tempo e espaço, buscou ocultar, de fato, o que produzia: aumento da pobreza resultante dos altos índices de desemprego:

A perversidade sistêmica que está na raiz dessa evolução negativa da humanidade tem relação com a adesão desenfreada aos comportamentos competitivos que atualmente caracterizam as ações hegemônicas. Todas essas mazelas são direta ou indiretamente imputáveis ao presente processo de globalização (SANTOS, 2001, p. 20).

Traz consigo, também, a premência em se homogeneizar produção e consumo para que a circulação de mercadorias não enfrente rejeição.

Para isso, sincronizou outros movimentos.

$\mathrm{Na}$ organização do trabalho, as marcas do fordismo - desde a fixação ao posto de trabalho às relações de trabalho - são sobrepostas pelas provenientes do toyotismo, que, contudo, propaga em grande escala a lógica à qual se vincula: produção enxuta, flexibilização nas contratações, terceirização e a ideia de uma maior participação dos trabalhadores no processo de trabalho, quando, de fato, ocorre a apropriação do conhecimento da força de trabalho para futuras medidas de racionalização da produção e consequente redução de pessoal ${ }^{1}$. O avanço da microeletrônica garantirá a padronização dos processos produtivos e a 
eliminação significativa do trabalho vivo, ampliando o mercado de trabalho informal.

A facção dos partidos à direita da política no Reino Unido, liderada por Margaret Thatcher, ataca o Estado Provedor, criado para recuperar os países dizimados na Segunda Guerra Mundial e conferir o acesso da população a direitos como saúde, educação e moradia, entre outros. O discurso da inoperância do Estado frente ao custeio de uma série de direitos alçou a iniciativa privada como mentora da administração pública, pois, na percepção dessa corrente, esta dominava os meandros para auferir lucros; e o Estado, por sua vez, conhecia unicamente os caminhos para despender recursos.

Os princípios do liberalismo conservador foram recuperados pelos idealizadores da Nova Gestão Pública (NGP). Para esse grupo, o Estado burocrático lento e com compromissos onerosos para assegurar direitos não correspondia ao dinamismo da sociedade emergente, robotizada e automatizada. No interior dessa lógica, é imperativa a passagem para um Estado gerencial, posto que a ineficiência prevalece no Burocrático.

O aumento do custo dos serviços do Estado impôs a adoção da Reforma Gerencial. Essa imposição, porém, não era apenas fiscal, mas também política. Para que o Estado Social se mantivesse legitimado em face da ofensiva neoliberal era necessário tornar suas ações substancialmente mais eficientes. Era necessário proceder à Reforma Gerencial (BRESSER-PEREIRA, 2010, p. 114).

É pitoresco que o ex-Ministro da Administração e Reforma do Estado (MARE) defenda um combate à "ofensiva neoliberal", sendo ele próprio importante agente desse movimento não somente no Brasil, como também na América Latina, pois construiu o arcabouço legal para uma série de medidas caracteristicamente neoliberais, entre elas o estabelecimento das parcerias públicoprivadas e a legitimação do "mercado" no interior do setor público, via Lei $\mathrm{n}^{\circ} 9.790$, de 23 de março de 1999.

Constata-se que a política pública rendeu-se aos princípios do setor privado e teve na década de 1990 a consolidação de um projeto ainda em curso.

A tão aguardada reformulação da Lei de Diretrizes e Bases (LDB), contemplou em 1996 certas conquistas, mas os defensores do gerencialismo foram os grandes vencedores. $\mathrm{Na}$ jogada ensaiada do partido político vencedor das eleições, constrói-se a lei e viabiliza-se um projeto nos estados, com destaque para São Paulo.

A matriz teórica presente na LDB elege o currículo baseado nas habilidades e competências em profícuo diálogo com o mundo empresarial. O pragmatismo exposto na política educacional dialoga com Milton Santos (2000) na perspectiva de fomentar a propagação de "deficientes cívicos", uma vez que são privilegiados conceitos como "competências", cujo sentido refere-se à aptidão em solucionar problemas cujos resultados possam ser mensurados. Esses, segundo Ropé e Tanguy (1997, p. 16),

[...] são justificados pela ideia de racionalização reivindicada pelos diferentes protagonistas que estão na sua origem e que vão desde os empresários, as autoridades governamentais, os construtores de referenciais, passando pelos cientistas convocados para dar legitimidade às práticas e representações que estão sendo construídas.

Assim, com base nas mesmas autoras, é possível afirmar que o padrão de competências assume um caráter científico, mas atende diretamente aos interesses do atual estágio do capitalismo.

É nesse contexto que uma série de formas de padronização se consolidam na política educacional, a partir de conteúdos, provas e aulas estandardizadas em nome de alçar melhores índices da educação, mas sem problematizar o que, de fato, os estudantes estão se apropriando e construindo um conhecimento capaz de formar cidadãos emancipados e com atuação na sociedade.

A Base Nacional Curricular Comum se tornará mais uma etapa na consolidação do projeto, como passamos a discutir.

\section{Base Nacional Comum Curricular: novo capítulo da educação em migalhas?}

"Maria, disse João, agora só nos resta seguir a trilha marcada com as migalhas de pão. Só que os passarinhos comeram todas as migalhas deixadas no caminho" (Irmãos Grimm, João $e$ Maria).

A análise do cenário brasileiro no contexto do pós-golpe indica a nítida construção de novos passos rumo à privatização da educação tanto endógena como exógena (BALL, YOUDELL, 2008). A Proposta de Emenda à Constituição 241 
(PEC 241/2016), popularmente conhecida como "PEC do Fim do Mundo", restringe os investimentos em educação, saúde, seguridade e outros segmentos por vinte anos. A ausência da participação do Estado em longo período pode ser apreendida em, ao menos, um duplo movimento: de um lado, tal medida permite a ação do setor privado no serviço público: a privatização está sendo, portanto, legalizada e incentivada, justificada como austeridade; ${ }^{2}$ do outro, compromete-se uma geração, com desdobramentos nefastos à população e ao país.

O Novo Regime Fiscal, válido para União, terá duração de vinte anos. Esse é o tempo que consideramos necessário para transformar as instituições fiscais por meio de reformas que garantam que a dívida pública permaneça em patamar seguro. Tal regime consiste em fixar meta de expansão da despesa primária total, que terá crescimento real zero a partir do exercício subsequente ao de aprovação deste PEC, o que levará a uma queda substancial da despesa primária do governo central como porcentagem do PIB. Trata-se de mudar a trajetória do gasto público federal que, no período 1997-2015 apresentou crescimento médio de $5,8 \%$ ao ano acima da inflação (PEC, 2016, s/p, grifos nossos).

Focalizando-se exclusivamente o Ministério da Educação observa-se que os cortes orçamentários inviabilizam a pesquisa científica e, simultaneamente, caminha-se para o sucateamento da educação e das universidades públicas. Ressaltese que essa estratégia foi altamente empregada durante o governo FHC para privatizar as estatais, a exemplo da telefonia. A ampla divulgação acerca da impossibilidade do setor público arcar com os custos da educação e a reafirmação do "mercado" como legítimo herdeiro das ações públicas nos levam a concluir que a privatização em larga escala está em curso, discurso que vem sendo reafirmado pela secretária executiva do MEC, Maria Helena Guimarães de Castro.

Assim, como na história de João e Maria em que as duas crianças lançam ao chão migalhas de pão para conseguir voltar para casa, mas que os pássaros as comem, não sendo possível retornar, a educação brasileira, que é de fundamental importância, vem vivendo de migalhas e a aprovação da Base Nacional Comum Curricular (BNCC) é mais um capítulo dessa história rumo à privatização.

A BNCC, promulgada e apresentada em sua versão final em dezembro de 2017, conta, desde o início, com inúmeras polêmicas. Por exemplo, o voto contra sua aprovação de três conselheiras do Conselho Nacional de Educação (CNE) que explicitaram haver pouca transparência na votação da Base, a partir de uma imposição do Ministério da Educação; de que esse documento é o currículo mínimo, suprimida qualquer menção às discussões de identidade de gênero, entre outros aspectos igualmente de grave teor.

$\mathrm{O}$ documento explicita que "redes de ensino e instituições escolares públicas e particulares passam a ter uma referência nacional obrigatória para a elaboração ou adequação de seus currículos e propostas pedagógicas" (BRASIL, 2017, p. 5, grifo nosso).

A nítida tentativa - pois se pressupõe a existência de resistência - de imposição da Base como referência imperativa a todas as redes de ensino, fará com que se definam as aprendizagens essenciais que os estudantes devem adquirir durante sua escolarização. Todavia, escolas privadas renomadas afirmam que não irão perseguir a BNCC, para a alfabetização, por exemplo, pois se configura como: "um retrocesso em relação a tudo que se aprendeu nos últimos 30 anos" (CAFARDO, PALHARES, 2017, s/p.).

O conjunto do documento merece atenção, como a antecipação da idade para alfabetização: "Nos dois primeiros anos do Ensino Fundamental, a ação pedagógica deve ter como foco a alfabetização" (BRASIL, 2017, p. 57), ou seja, as crianças devem, por decreto, estar alfabetizadas até os 7 anos de idade. Esse aspecto difere do documento publicado em 2012 pelo MEC, que institui o ciclo de alfabetização contemplando os três primeiros anos de escolarização, indicando, portanto, a alfabetização até os 8 anos de idade (BRASIL, 2012).

Destaque-se, igualmente, a apresentação dos conteúdos e conceitos a serem aprendidos pelos estudantes em todos os componentes curriculares e por ano de escolarização, contando com a seguinte estrutura: unidade temática, objeto de conhecimento e habilidades a serem desenvolvidas.

No quadro a seguir um exemplo de leitura em Língua Portuguesa do $6^{\circ}$ ao $9^{\circ}$ anos do Ensino Fundamental. 
Quadro 1: exemplo de unidade temática, objeto de conhecimento e habilidades apresentadas na BNCC

\begin{tabular}{|c|c|l|}
\hline $\begin{array}{c}\text { Práticas de } \\
\text { Linguagem }\end{array}$ & Objeto de Conhecimento & \multicolumn{1}{|c|}{ Habilidades } \\
\hline Leitura & $\begin{array}{c}\text { Estratégia de leitura: } \\
\text { apreender os sentidos } \\
\text { globais do texto }\end{array}$ & $\begin{array}{l}\text { (EF69LP03) Identificar, em notícias, o fato central, suas principais } \\
\text { circunstâncias e eventuais decorrências; em reportagens e } \\
\text { fotorreportagens o fato ou a temática retratada e a perspectiva de } \\
\text { abordagem, em entrevistas os principais temas/subtemas abordados, } \\
\text { explicações dadas ou teses defendidas em relação a esses subtemas; em } \\
\text { tirinhas, memes, charge, a crítica, ironia ou humor presente. }\end{array}$ \\
\cline { 2 - 4 } & $\begin{array}{l}\text { EF69LP04) Identificar e analisar os efeitos de sentido que fortalecem a a } \\
\text { persuasão nos textos publicitários, relacionando as estratégias de } \\
\text { persuasão e apelo ao consumo com os recursos linguístico-discursivos } \\
\text { utilizados, como imagens, tempo verbal, jogos de palavras, figuras de } \\
\text { linguagem etc., com vistas a fomentar práticas de consumo conscientes. } \\
\text { (EF69LP05) Inferir e justificar, em textos multissemióticos - tirinhas, } \\
\text { charges, memes, gifs etc. -, o efeito de humor, ironia e/ou crítica pelo } \\
\text { uso ambíguo de palavras, expressões ou imagens ambíguas, de clichês, } \\
\text { de recursos iconográficos, de pontuação etc. }\end{array}$ \\
\hline
\end{tabular}

Fonte: (BRASIL, 2017, p. 138-139).

É importante observar que a apresentação das habilidades estabelece estreito diálogo com os descritores nas Matrizes de Referência das avaliações em larga escala, como no $\mathrm{Saeb}^{3}$. O referido documento indica para habilidades de leitura:

D1 - Localizar informações explícitas em um texto.

D3 - Inferir o sentido de uma palavra ou expressão.

D4 - Inferir uma informação implícita em um texto.

D6 - Identificar o tema de um texto.

Portanto, apreende-se que a demanda ao estudante é idêntica tanto na BNCC quanto na Matriz de Referência, mesmo que com maior detalhamento na BNCC. A despeito do exemplo, constata-se haver essa mesma lógica nos demais componentes curriculares.

Registre-se, igualmente, que em algumas habilidades são indicadas situações impossíveis de ser avaliadas em uma prova com questões objetivas, como na de geometria para o $6^{\circ}$ ano do Ensino Fundamental: "(EF06MA22) Utilizar instrumentos, como réguas e esquadros, ou softwares para representações de retas paralelas e perpendiculares e construção de quadriláteros, entre outros" (BRASIL, 2017, p. 300-301), mas em muitos outros casos, como no exemplo apresentado em Língua Portuguesa isso, de fato, ocorre.
A concepção presente na BNCC vinculada às avaliações de grande escala, incorre, em nossa compreensão, na agudização das tensões no interior da escola e, consequente, degradação das condições de trabalho e adoecimento dela decorrentes. Estudos indicam que as pressões para lograr êxito nos processos de avaliação sustentam-se em, ao menos, dois pilares: atender à lógica dos resultados pode significar pagamento de gratificações, a exemplo do estado de São Paulo, não desprezíveis, apesar da variação monetária, em razão dos baixos salários praticados à categoria; mas, concomitantemente tangencia o sentido do trabalho realizado.

Entrevistas realizadas junto a professores da rede estadual paulista indicam que o sentimento gerado pelo ranqueamento das escolas é de frustração profissional, posto que tendem a tomar para si o fracasso escolar, fomentado pela padronização da educação e das mensurações (VENCO, 2016; GONÇALVES \& VENCO, 2015). Assim, constatase que a vinculação da BNCC às avaliações acirrará uma prática recorrente: a redução do currículo das disciplinas escolares às habilidades presentes na Base.

Além disso, consideramos que essa é uma tentativa de prescrever o trabalho intelectual e controlar as atividades desenvolvidas em sala de aula, sobretudo a partir do movimento "Escola sem partido", cuja veiculação pela mídia ao lado de pressões religiosas levaram à supressão das questões de gênero, no documento. 
Visando contribuir para o debate aprofundado sobre o tema, passamos a apresentar os artigos que compõem esse número temático.

Os artigos publicados nesse número apresentam duas perspectivas distintas. Na primeira delas, são apresentados 4 artigos que trazem contribuições, de modo geral, sobre a BNCC, propondo-se a discutir a elaboração desse documento e as ideias nele ocultadas; a construção da BNCC pela mídia; a participação docente na sua elaboração; e, a educação infantil nesse documento. A segunda perspectiva, constituída por 7 textos, relaciona-se às áreas de conhecimento, quais sejam: Artes, Língua Portuguesa, Educação Física, Matemática e Ciências Naturais.

\section{A Base Nacional Comum Curricular: perspectivas, desafios e dilemas}

O primeiro artigo, de Eduardo Donizeti Girotto, intitulado "Entre o abstracionismo pedagógico e os territórios de luta: a Base Nacional Comum Curricular e a defesa da escola pública", apresenta reflexões sobre a construção e a perspectiva implícitas no documento e indica uma relação intrínseca entre escola, espaço e sociedade, a qual não pode ser negada, e que reduz a escola a um lugar de reprodução dos interesses da classe dominante. Nos convida a refletir, outrossim, sobre a aproximação da BNCC às avaliações em larga escala que podem aumentar o controle sobre a escola e sobre o trabalho do professor, também como uma maneira de fragilizar a formação docente devido à lógica empresarial e ao avanço do neoliberalismo. Para Girotto esse é um projeto de currículo que amplia, ainda mais, o abismo das desigualdades sociais e da precarização da educação brasileira.

"A construção da Base Nacional Comum Curricular na mídia: que atores e posições foram veiculados pelo jornal Folha de São Paulo?" de Pricila de Fátima Stankevecz e Noela Invernizzi Castillo, visa identificar os atores e os temas debatidos sobre a BNCC no referido periódico, posto que, segundo as autoras, a mídia, em seu papel de formadora de opinião, exerce papel fulcral na divulgação das ideias com vistas à aceitação da política pública. A análise das notícias divulgadas na mídia é importante uma vez que atua diretamente na explicitação das perspectivas e interesses dos diferentes grupos. Assim, partindo de diferentes questionamentos, as autoras realizaram uma pesquisa bibliográfica, documental e hemerográfica em que utilizaram a análise de conteúdo em relação às matérias publicadas nesse jornal.

Nathália Fernandes Egito Rocha e Maria Zuleide da Costa Pereira, assinam o texto "A prosopopeia da Base Nacional Comum Curricular e a participação docente", cujo escopo visa refletir a propósito do caráter não democrático da proposta, cuja participação de professores ocorreu de maneira puramente formativa, de acordo com as autoras. Assim, a noção de prosopopeia em Bourdieu, no sentido de figura retórica, aponta para a fala ventríloqua de um agente em nome do Estado. Rocha e Pereira, dão, portanto, voz aos professores e evidenciam as concepções presentes na relação entre a BNCC e o contexto das práticas escolares.

$\mathrm{O}$ último artigo desse bloco discute os aspectos mais gerais da BNCC: "A Base Nacional Comum Curricular e o berçário" de Fabiana Cristina Frigieri de Vitta, Girlene de Albuquerque Cruz e Bárbara Solana Scarlassara, no qual analisam a Base no que se refere à Educação Infantil no berçário. As autoras explicitam que, para a Educação Infantil, a BNCC complementa as Diretrizes Curriculares Nacionais para a Educação Infantil de 2010, uma vez que este último não apresentava os conteúdos e objetivos educacionais para esse segmento.

\section{A BNCC e os componentes curriculares}

Os três primeiros artigos trazem discussões que abordam a composição curricular de: Arte, Língua Portuguesa e Educação Física.

O primeiro texto, de Rosa Iavelberg, "A Base Nacional Curricular Comum e a formação dos professores de arte" tem como objetivo identificar as continuidades e descontinuidades dos Parâmetros Curriculares Nacionais (PCN) para a BNCC e, para isso, analisa a terceira versão desse documento no que se refere ao ensino de Arte nos anos iniciais do Ensino Fundamental. A autora explicita que esse documento oficial propõe importante mudança nos currículos de Arte na Educação Básica, com implicações diretas nos livros didáticos, currículos escolares, projetos político- pedagógicos e na formação de professores. Dessa forma, Iavelberg contribui para o debate na área enfatizando, inclusive, a unidade temática Artes Integradas, ausente nos PCNs, cujo enfoque integra as Artes Visuais, a Dança, a Música e o Teatro.

"Os gêneros orais na penúltima versão da Base Nacional Comum Curricular: implicações para o ensino" de autoria de Ana Elisa Jacob, Kátia Diolina e Luzia Bueno investiga os conteúdos 
referentes a gêneros textuais em Língua Portuguesa nos anos finais do Ensino Fundamental. As autoras compreendem que o documento tem o papel de nortear os conteúdos que serão ensinados e, por isso, apresenta implicações para as ações do professor em sala de aula, posto que assume um caráter normativo. Destacam, igualmente, o teor político e ideológico que tende a legitimar alguns conteúdos em detrimento de outros. Assim, é tecida a devida problematização sobre as consequências para o ensino de gêneros orais, pois esses são ferramentas de ação e transformação das maneiras de agir, sejam a prática e ou a comunicacional.

Discutir sobre a Base e a perspectiva de diversidade cultural a partir do currículo cultural da Educação Física é o objetivo do artigo "Base Nacional Comum Curricular e currículo da Educação Física: qual o lugar da Diversidade cultural?" de Marcio Antonio Raiol dos Santos e Pedro Paulo Souza Brandão. Para tanto, os autores trazem sua compreensão sobre diversidade cultural como um fenômeno e também suas implicações para o currículo da escola, no que se refere à Educação Física no Ensino Fundamental, e focalizam como a questão da diversidade cultural vem sendo contemplada na Lei de Diretrizes e Bases da Educação Nacional e nos Parâmetros Curriculares Nacionais e na Base, buscando indícios de como esse documento aborda o tema e quais as aproximações e rupturas entre eles.

Dois artigos dedicam-se à Matemática nos anos iniciais do Ensino Fundamental.

$\mathrm{O}$ primeiro deles, de Emerson Rolkouski, "Dos direitos de aprendizagem e do Pacto Nacional pela Alfabetização na Idade Certa à Base Nacional Comum Curricular: o caso da alfabetização matemática" debate a alfabetização matemática presente na BNCC e, para isso, buscou aporte nos Elementos Conceituais e Metodológicos para a Definição dos Direitos de Aprendizagem e Desenvolvimento do Ciclo de Alfabetização do Ensino Fundamental, documento publicado em 2012, e no Pacto Nacional pela Alfabetização na Idade Certa - PNAIC (MEC). Para tanto, enfatiza a elaboração dos Cadernos utilizados para a formação de professores nesse programa. E, por fim, apresenta aproximações e distanciamentos com relação à BNCC.

$\mathrm{O}$ artigo intitulado "O currículo de matemática dos anos iniciais do ensino fundamental na base nacional comum curricular (BNCC): os subalternos falam?" de Maria José Costa dos Santos objetiva analisar, a partir da BNCC, as reformas curriculares e sua viabilização para o ensino de matemática nos anos iniciais do Ensino Fundamental. Com este objetivo, a autora discute os objetos de conhecimento, o direito de aprender, a participação dos professores na elaboração de políticas públicas e a implementação desse documento. Assim, Santos pauta-se na literatura que aborda a formação do professor, o currículo de matemática e a avaliação, relacionando-os às políticas públicas e à participação docente nas discussões sobre esses temas, principalmente na elaboração da BNCC.

Por fim, as Ciências da Natureza são contempladas em dois artigos: "Um olhar para o discurso da Base Nacional Comum Curricular em funcionamento na área de ciências da natureza" de Cristhiane Carneiro Cunha Flôr e Guilherme Trópia, cuja finalidade é responder a um questionamento: que leituras possíveis podemos fazer da BNCC em relação aos textos que a fundamentam? Para essa discussão, os autores apropriam-se de conceitos da Análise de Discurso de Linha Francesa e analisam diferentes partes do documento, especialmente no que se refere à área de ciências da natureza. Segundo os autores, a BNCC, ao definir o conjunto de aprendizagens essenciais a ser adquirido ao longo da escolarização, traz fortemente a ideia de uniformização. Assim, os diferentes grupos que a elaboraram trouxeram várias perspectivas como a padronização dos conteúdos a serem ensinados, o resultado nas avaliações em larga escala e a necessidade de suprir lacunas na formação dos professores e na organização dos sistemas de ensino.

Luiz Gustavo Franco e Danusa Munford, autores de "Reflexões sobre a Base Nacional Comum Curricular: um olhar da área de Ciências da Natureza", refletem sobre o processo de elaboração da BNCC e interpelam as especificidades da área de ciências da natureza, além de questões relacionadas à formação de professores. Dessa forma, os autores analisaram as diferentes versões do documento que evidenciam mudanças que, no seu entendimento, comprometem a educação em ciências, pois enfatizam-se aspectos conceituais, contudo com ausência de articulação com outras áreas do conhecimento. Dessa forma, os autores apresentam uma cronologia da elaboração das versões da BNCC na perspectiva do contexto político e discutem sobre as propostas para as Ciências Naturais, focando as alterações que a Base sofreu e problematizando as consequências de tais mudanças para o ensino dessa área do conhecimento. 


\section{Algumas ponderações}

A partir das considerações por nós tecidas e à luz da contribuição dos autores que compõem esse número temático, retomamos a proposição do título: por que, então, a BNCC alimentaria a divisão de classes? As estatísticas indicam que praticamente nove em cada dez estudantes, em todo o país, estão matriculados nas escolas públicas. Essas, por sua vez, com algumas exceções, atenderão às normas do Ministério da Educação, aqui sendo discutida particularmente a Base. Como visto em declarações nos jornais, as escolas que formam a elite do país não se submeterão a ela, pois concordam que o documento representa um profundo retrocesso à educação. A mensagem porta um teor claro: esse modelo está em desacordo com a formação esperada para e pela classe que representam.

Como aponta Marília Fonseca (2009), a qualidade de ensino é compreendida pela política sempre que ela atender às demandas do capitalismo.

Nesse sentido, constata-se que com essa formação e com a redução orçamentária para a educação, o Brasil continuará inscrevendo-se subalternamente na economia mundial, acolhendo calorosamente e submissamente o capital internacional, que permanecerá explorando as pessoas e o território. Este capital tem nas avaliações em grande escala, nacionais e internacionais, uma ferramenta para decidir sobre a propagação de uma terceirização predadora em direção aos países semiperiféricos, como o Brasil.

Recuperamos aqui o título do presente artigo, um excerto de entrevista realizada por Walkiria Rigolon (2013), com alto escalão da Secretaria Estadual de Educação, altamente ilustrativo sobre o pensamento dos formuladores da política e que reforça nossa compreensão acerca da inserção brasileira na economia mundial, sobretudo frente às ações empreendidas no contexto pós-golpe 2016, com nítidos sinais de preparação para a privatização da educação.

Consoante com Patto (2010) sobre as metas empreendidas pela educação brasileira alinhadas com organismos internacionais, é importante destacar as intencionalidades ocultadas por um discurso dissimulado em prol da educação de qualidade. Para a autora, os objetivos de tal opção política visam: a) lograr alguns objetivos, quais sejam: redução de custos com a educação e ajustá-la à economia que rege a ordem mundial; b) ampliar as estatísticas sobre a escolaridade da população, sem considerar, contudo, a qualidade da educação; c) conferir aos "excluídos a ilusão que estão sendo incluídos na escola e, pela obtenção do diploma, no universo do trabalho" (p.33).

A BNCC é, assim, no nosso entendimento, mais uma "pá de cal” na educação pública.

\section{Notas}

1 Sobre isso ver: BIHR, Alain. Da grande noite à alternativa - o movimento operário em crise. São Paulo: Boitempo, 1998.

2 Sobre isso consultar: "Austeridade e Retrocesso". Disponível em: <http://brasildebate.com.br/wpcontent/uploads/Austeridade-e-Retrocesso.pdf $>$.

3 Disponível em: <http://portal.inep.gov.br/web/gue st/educacao-basica/saeb/matrizes-e-escalas $>$. Acesso em: 12 abr. 2018.

\section{Referências}

BALL, S. J.; YOUDELL, D. Hidden privatisation in public education: Education International, Brussels, 2008

BRASIL. Câmara dos Deputados. Proposta de emenda constitucional 241/2016. Disponível em < http://www.camara.gov.br/proposicoesWeb/fichadet ramitacao?idProposicao $=2088351>$ Acesso em 19.abr.2018.

BRASIL. Ministério da Educação. Base Nacional Comum Curricular. Brasília: MEC, 2017.

BRASIL. Ministério da Educação, Secretaria de Educação Básica. Elementos conceituais e metodológicos para definição dos direitos de aprendizagem e desenvolvimento do ciclo de alfabetização $\left(1^{\circ}, 2^{\circ} \mathrm{E} 3^{\circ}\right.$ anos $)$ do Ensino Fundamental. Brasília: MEC, 2012.

BRESSER-PEREIRA, L.C. Da administração pública burocrática à gerencial. Revista do Serviço Público, v. 47, n.1, 1996. Disponível em: <https://revista.enap.gov.br/ index.php/RSP/issue/view/84> Acesso em 15.abr.2018.

. Democracia, estado social e reforma gerencial. Revista Administração de Empresas, São Paulo, v. 50, n. 1, p. 112-116, mar. 2010. Disponível em: 
<http://www.scielo.br/scielo.php?script=sci_arttext $\&$ pid=S003475902010000100009\&lng=en\&nrm=is o>. Acesso em: 15 abr. 2018.

CAFARDO, R.; PALHARES, I. Escolas de São Paulo discordam de Base Nacional Curricular Comum. Estadão. Disponível em: $<$ http://educacao.estadao.com.br/noticias/geral, escolas-de-sao-paulo-discordam-de-base-nacionalcurricularcomum,70 002078885>. Acesso em: 16 abr. 2018.

FONSECA, M. Políticas públicas para a qualidade da educação brasileira: entre o utilitarismo Econômico e a responsabilidade social. Caderno Cedes. Campinas, v. 29, n. 78, p. 153-177, maio/ago. 2009.

GONÇALVES, E.D., VENCO, S. Progressão na carreira mediante violação de direitos. Anais XI Seminario Internacional de la Red Estrado. Disponível em <http://redeestrado.org/xi_seminario/pdfs/eixo2/213 .pdf> Acesso em 19.abr.2018.

LIMA, R. Mercado de trabalho e a teoria da segmentação. Pesquisa e planejamento econômico. Rio de Janeiro, v. 10, n. 1, abr. 1980.

PATTO, M.H. Exercícios de indignação: escritos de educação e psicologia. São Paulo: Casa do
Psicólogo, 2010.

RIGOLON, W.O. O que muda quando tudo muda? Uma análise do trabalho docente dos professores alfabetizadores do estado de São Paulo. Tese de doutorado apresentada ao Programa de Pósgraduação em educação, Faculdade de Educação, Unicamp, 2013.

ROPÉ, F., TANGUY, L. Saberes e Competências. São Paulo: Papirus, 2005.

SANTOS, M. Por uma outra globalização. Rio de Janeiro: Record, 2001. . Os deficientes cívicos. Folha de $S$. Paulo, 2000. Disponível em <http://www1.folha.uol.com.br/fol/brasil500/dc_3_ 9.htm> Acesso em 19.abr.2018.

SCHULTZ, T.W. O valor econômico da educação. Rio de Janeiro: Zahar, 1973.

SMITH, A. Riqueza das nações. Lisboa: Fundação Calouste Gulbenkian, 1993.

VENCO, S. Precariedades: desdobramentos da Nova Gestão Pública. Crítica e Sociedade: Revista de Cultura Política. v. 6, n. (1), 2016. Disponível em <http://www.seer.ufu.br/index.php/criticasociedade/ article/view/36341> Acesso em 19.abr.2018.

\section{Sobre os autores}

Selma Borghi Venco: Socióloga, mestre e doutora em educação pela Universidade Estadual de Campinas, com ênfase em trabalho e educação. Realizou dois pós-doutorados:IFCH, no departamento de sociologia; e Laboratoire Genre, Travail et Mobilités, Univeristé Paris X. Atualmente é docente na Faculdade de Educação da Universidade Estadual de Campinas (UNICAMP), Departamento de Políticas, Administração e Sistemas Educacionais (DEPASE) e pesquisadora associada do Centre de Recherches Sociologiques et Politiques de Paris (CRESPPA). É vice-líder do Grupo de Estudos e em Política Educacional (GREPPE) e participa de duas linhas de pesquisa: Política educacional e Trabalho e Educação. O trabalho docente na educação básica é foco de pesquisa desde 2010 e atualmente desenvolve pesquisa sobre a pesquisa educacional no Brasil e França e os desdobramentos para o trabalho docente.

Reginaldo Fernando Carneiro: Doutor em Educação pela Universidade Federal de São Carlos - UFSCar e licenciado em Matemática também por essa instituição. Atualmente é professor da Faculdade de Educação da Universidade Federal de Juiz de Fora - UFJF - e dos Programa de Pós-Graduação em Educação e em Educação Matemática do qual é vice-coordenador. Coordena o Grupo de Estudos e Pesquisas em Educação Matemática GREPEM - da UFJF e é pesquisador do GEM da UFSCar. É membro da Diretoria Nacional Executiva da Sociedade Brasileira de Educação Matemática - SBEM - gestão 2016-2019. Tem como interesse de pesquisa a formação de professores que ensinam matemática. 